\title{
Individual health reflected in the collectivity
}

\author{
Ildefonso Rodriguez-Leyva*
}

Department of Neurology, Faculty of Medicine, Hospital Central "Dr. Ignacio Morones Prieto," Universidad Autónoma de San Luis Potosí, San Luis Potosí, Mexico

It all started in December 2019, the authorities of the Chinese Health Services reported the presence of several cases of pneumonia in the city of Wuhan, China. The following month, the Shanghai Public Health Clinical Center and the School of Public Health, showed the complete genomic sequence of the 2019-nCoV warning of how this infection could affect not a few but thousands of individuals. The first reported case in the United States occurred in a young man who had visited Wuhan'.

The most interest aspect is that person-to-person transmission is demonstrated and that an asymptomatic and healthy young woman with a positive real-time polymerase chain reaction test for COVID-19 who lives in Wuhan visited her family in the province of Anyang, China, and developed a cluster of familial pneumonia in an incubation period of 1-19 days ${ }^{2}$.

Most of the cases have occurred in adult people 3079 years (87\%), and only $1 \%$ in people younger than 9 years of age. Furthermore, being in a city, it extended in just 30 days to all of China, February 18,2020 , reported 72,528 confirmed cases of COVID-19 (99\% of the global total) and 1870 deaths $(99.8 \%$ of the global total), with more than 3000 cases in health personnel. The sanitary measures were isolation, quarantine, social distancing, and community contention. By February 20, 2020, 1073 cases had already been reported outside of China $^{3}$.
On February 7, 2020, the WHO Scientific and Technical Advisory Group for Infectious Hazards issued a series of recommendations to try to stop the spread of COVID-19. They were emphasizing that although the transmission was possibly initially from animals (bat) to humans, it is clear that the spread is occurring by human-human transmission. Insisting that although the fatality is challenging to determine, the lung affection mainly like pneumonia, is the most critical $(1-2 \%)$, although lower than for severe acute respiratory syndrome (10\%). Transmission is possibly oral, so conglomerations should be avoided. Moreover, it also seems that the most affected are older adults with comorbidities. The WHO insists on the advisability of suspending public activities (especially with high attendance) and also closing schools, working remotely, making phone calls, and using telemedicine. Besides, they suggest maintaining and having the ventilatory support equipment, oxygen, and extracorporeal membrane oxygenation equipment to be ready for as soon as it is necessary to use ${ }^{4}$.

In addition to the above, we must consider that just as animal-human and then human-human transmission occurred initially, human-animal (pets) transmission may also be feasible and thus further spread the problem $^{5}$.

Despite the measures taken by the Chinese government and the warnings issued by the $\mathrm{WHO}$, cases of

\section{Correspondence:}

*lldefonso Rodriguez-Leyva

Faculty of Medicine

Hospital Central "Dr. Ignacio Morones Prieto"

Universidad Autónoma de San Luis Potosí Date of reception: 15-03-2020

San Luis Potosí, Mexico

E-mail: ilrole@yahoo.com.mx
Date of reception: $15-03-2020$

DOI: $10.24875 /$ RMN.M20000078
Available online: 05-08-2020

Rev Mex Neuroci. 2020;21(4):122-123 www.revmexneurociencia.com

1665-5044/ @ 2020 Academia Mexicana de Neurología A.C. Published by Permanyer. This is an open access article under the CC BY-NC-ND license (http://creativecommons.org/licenses/by-nc-nd/4.0/). 
pneumonia began to appear in the Milan metropolitan area, which ended in a health problem that finally isolated the country entirely ${ }^{6}$.

In an "invisible" spread, the problem grew and spread from Milan to Lyon, France, and Alitalia passengers arriving in Mauritius were quarantined. Some countries outside Europe began to reject passengers from Italy. Four people in the UK were confirmed positive for COVID-19 and had been on the Diamond Princess cruise. South Korea reported almost 1000 affected, and the problem continued to grow ${ }^{7}$.

The problem in Italy began on January 31,2020 , with two Chinese visitors who were staying in a central hotel in Rome and had landed at Milan's Malpensa Airport on January 23. Just a month later, the Prime Minister of Italy declared the situation to be a national emergency ${ }^{8}$.

As this is being written, COVID-19 Global Cases by the Center for Systems Science and Engineering at Johns Hopkins University reports 179,029 confirmed cases of COVID-19, 7057 deaths, and only 78,073 fully recovered ${ }^{9}$. The spread includes an increasing number of cases, from highest to lowest, in China, Italy, Iran, Spain, South Korea, Germany, France, the USA, the UK, and Holland.

Although this is only a partial view of what happened in a pandemic that has grown exponentially, it shows us that measures as old and simple as social isolation, quarantine, public containment, and keeping our hospitals ready for who requires them are vital measures.
Measures that are needed to avoid problems that could massively affect a high percentage of the population.

It is evident in this brief story that the health of an individual in an infectious-contagious problem can affect an entire community. The preventive health measures taken by countries such as France, Spain, Italy, the United States, and, of course, China itself should be an example to all the nations. Therefore, we must apply what to do and what to avoid; apparent health does not seem to be enough, although older adults with comorbidities are the most susceptible. Let us hope that our health systems manage to be sufficient and adequate for a problem that can potentially affect all the populations of Latin America.

\section{References}

1. Paules $\mathrm{Cl}$, Marston $\mathrm{HD}$, Fauci AS. Coronavirus infections-more than just the common cold. JAMA. 2020;323:707-8.

2. Bai $Y, Y a o L$, Wei $T$, Tian $F$, Jin DY, Chen $L$, et al. Presumed asymptomatic carrier transmission of COVID-19. JAMA. February 21, 2020 [Epub ahead of print].

3. Wu Z, McGoogan JM. Characteristics of and important lessons from the coronavirus disease 2019 (COVID-19) outbreak in China: summary of a report of 72314 cases from the Chinese center for disease control and prevention. JAMA. February 24, 2020 [Epub ahead of print].

4. Heymann DL, Shindo N, WHO Scientific and Technical Advisory Group for Infectious Hazards. COVID-19: what is next for public health? Lancet. 2020;395:542-5.

5. Bonilla-DK BB, Rabaan A, Gomez WE, Rodriguez-AJ RR. Una nueva zoonosis viral de preocupación global: COVID-19, enfermedad por coronavirus 2019. latreia. 2020;33:107-10.

6. Spina S, Marrazzo F, Migliari M, Stucchi R, Sforza A, Fumagalli R. The response of Milan's emergency medical system to the COVID-19 outbreak in Italy. Lancet. 2020;395:e49-50.

7. Day M. Covid-19: surge in cases in Italy and South Korea makes pandemic look more likely. BMJ. 2020;368:m751.

8. Carinci F. Covid-19: preparedness, decentralisation, and the hunt for patient zero. BMJ. 2020;368:m799.

9. Available from: https://coronavirus.jhu.edu/map.html. 